\title{
Urdimento
}

Revista de Estudos em Artes Cênicas

E-ISSN: 2358.6958

\section{Qual o futuro da disciplina Arte a partir da BNCC do Ensino Médio?}

Tiago Cruvinel

\section{Para citar este artigo:}

CRUVINEL, Tiago. Qual o futuro da disciplina Arte a partir da BNCC do Ensino Médio? Urdimento, Florianópolis, v. 1, n. 40, mar./abr. 2021.

do) DOI: http:/dx.doi.org/10.5965/1414573101402021e0206

Este artigo passou pelo Plagiarism Detection Software | iThenticate 


\title{
Urdimento
}

Qual o futuro da disciplina Arte a partir da BNCC do Ensino Médio?

\section{Resumo}

Tiago Cruvinel ${ }^{1}$

Este artigo propõe uma discussão sobre a estrutura da BNCC (Base Nacional Comum Curricular) do Ensino Médio, de modo a analisar os conceitos de competência gerais que sustentam o documento, a partir da teoria de Philippe Perrenoud. Este texto é o resultado da pesquisa de pós-doutorado do autor. Trata-se de uma contribuição aos docentes de Arte (Teatro, Dança, Artes Visuais ou Música), no intuito de auxiliá-los na elaboração de um pensamento crítico e estratégico para lidar com a BNCC, que se encontra em vias de implementação em todos os estados brasileiros. Ao final, é proposta uma reflexão sobre o futuro da disciplina Arte no atual contexto político.

Palavras-chave: Educação. Arte. BNCC. Competências. Habilidades.

What is the future of the Art discipline from the Highschool's BNCC?

\begin{abstract}
This article proposes a discussion regarding the Highschool BNCC (National Common Curricular Base) structure, in order to analyze the general competence that sustain the documentation, based on the Philippe Perrenoud's theory. This text is the result of the author's post-doctorate degree research that has been used by Art teachers (Drama, Dance, Visual Arts or Music), with the main purpose being to help elaborate critical and strategic thinking as to deal with the BNCC, which is being implemented in all Brazilian states. The theory on which is currently being proposed towards a more in-depth reflection about the future of the Art discipline within the current political context.
\end{abstract}

Keywords: Education. Art. BNCC. Competences. Abilities.

\footnotetext{
${ }^{1}$ Professor do Instituto Federal de Minas Gerais (IFMG). Formado em Interpretação Teatral (2010) e licenciatura em Artes Cênicas (2015) pela Universidade de Brasília (UnB). Realizou intercâmbio durante a primeira graduação na Faculdade de Belas Artes da Universidade do Porto, Portugal. É mestre (2013) e doutor (2017) em Artes pela UnB, com Pós-Doutorado na Escola de Belas Artes da Universidade Federal de Minas Gerais - UFMG (2019), sob supervisão da professora Mariana Lima Muniz, e Pós-Doutorado em Artes Cênicas na Escola de Comunicações e Artes da Universidade de São Paulo - USP (2020), sob supervisão da professora Maria Lúcia Pupo. Ganhador do prêmio de melhor Tese na área de Linguística, Letras e Artes junto ao Prêmio UnB Tese do ano de 2017. Autor do livro Criança em cena: Análise da atuação e de processos criativos com crianças-atores (Editora CRV, 2015) e um dos organizadores dos livros Pedagogia das Artes Cênicas (Volume 1, 2, 3 e 4). Foi vice-coordenador do grupo de trabalho Pedagogia das Artes Cênicas da Associação Brasileira de Pesquisa e Pós-Graduação em Artes Cênicas ABRACE (2017-2018). É pesquisador associado do Groupe de Recherche sur l'Enseignement du Théâtre - GRET da Université du Québec à Montréal - (UQAM). Atualmente é colaborador do Mestrado Profissional em Artes (ProfArtes) da UFMG e realiza seu terceiro pós-doutorado no CEFET-MG sobre a elaboração de livro didático em Arte a partir da Teoria Queer. tiago.brito.cruvinel@gmail.com

(9) http://lattes.cnpq.br/1147264803853400

http://orcid.org/0000-0002-1808-0753
} 


\section{Urdimento}

¿Cuál es el futuro de la disciplina Arte del BNCC de la escuela secundaria?

\section{Resumen}

Este artículo propone una discusión sobre la estructura del BNCC (Base Nacional Común Curricular) de la escuela secundaria, con el fin de analizar los conceptos de competencia y habilidades específicas que sustentan el documento, como la teoría de Philippe Perrenoud. Este texto es el resultado de la investigación postdoctoral del autor. Es un aporte a los profesores de Arte (Teatro, Danza, Artes Visuales o Música), con el fin de asistirlos en el desarrollo del pensamiento crítico y estratégico para enfrentar el BNCC, el cual se está implementando en todos Estados brasileños. Al final, se propone una discusión acerca del futuro de la disciplina Arte en el contexto político actual.

Palabras clave: Educación. Arte. BNCC. Competencia. Habilidades. 


\section{Introdução}

No momento em que o Ministério da Educação propõe uma Base Nacional Comum Curricular (BNCC) que abranja todo o território nacional, em um país com tantas desigualdades sociais como o Brasil, isto é, enquanto houver uma discrepância em relação ao Índice de Desenvolvimento Humano (IDH) nas regiões Norte e Sul do país, por exemplo, o documento já está fadado ao fracasso. Por esse motivo, não é de se estranhar que haja tanta resistência de diferentes educadores e profissionais da Educação à implementação desse tipo de documento. Qualquer caminho em direção à equidade, que vise a minimizar as desigualdades, precisa passar, também, por mudanças significativas e estruturantes nas esferas econômica, social e cultural, o que não vem ocorrendo no Brasil.

Dada a realidade em que nos encontramos e a crescente desvalorização da atividade docente por parte da extrema direita brasileira, tais como o Movimento Escola sem Partido, precisamos compreender a estrutura da BNCC, uma vez que ela já está em via de efetivação nos estados e nos municípios. O prazo de implementação será o ano de 2022. Além disso, é fundamental² a discussão sobre os conceitos de competência e habilidade que sustentam o documento. Sem omitir nenhuma crítica ao documento e ao contexto no qual ele foi criado, pretende-se aqui auxiliar todas as docentes e todos os docentes de Arte (Teatro, Dança, Artes Visuais ou Música), também aqueles que estão em processo de formação, a criarem um pensamento crítico e estratégico para lidarem com a BNCC.

A Base Nacional Comum Curricular (BNCC), entendida como um instrumento fundamental para garantir um nível comum de aprendizagem a todos(todas) os(as) estudantes desenvolveu dez competências gerais que devem ser trabalhadas

2 As expressões "é fundamental", "é preciso", "deve ser", entre outras afirmações ao longo do texto, utilizadas de forma imperativa no texto, tratam-se da minha opinião, a partir das minhas leituras e da pesquisa desenvolvida, o que implica, naturalmente, que outros possam pensar de forma diferente. Portanto, para evitar a repetição de termos como "na minha opinião", "a meu ver", manterei a estrutura textual tal como proposta. 
durante toda a Educação Básica (Brasil, 2018).

São elas:

1. Valorizar e utilizar os conhecimentos historicamente construídos sobre o mundo físico, social, cultural e digital para entender e explicar a realidade, continuar aprendendo e colaborar para a construção de uma sociedade justa, democrática e inclusiva.

2. Exercitar a curiosidade intelectual e recorrer à abordagem própria das ciências, incluindo a investigação, a reflexão, a análise crítica, a imaginação e a criatividade, para investigar causas, elaborar e testar hipóteses, formular e resolver problemas e criar soluções (inclusive tecnológicas) com base nos conhecimentos das diferentes áreas.

3. Valorizar e fruir as diversas manifestações artísticas e culturais, das locais às mundiais, e também participar de práticas diversificadas da produção artístico-cultural.

4. Utilizar diferentes linguagens - verbal (oral ou visual-motora, como Libras, e escrita), corporal, visual, sonora e digital -, bem como conhecimentos das linguagens artística, matemática e científica, para se expressar e partilhar informações, experiências, ideias e sentimentos em diferentes contextos e produzir sentidos que levem ao entendimento mútuo.

5. Compreender, utilizar e criar tecnologias digitais de informação e comunicação de forma crítica, significativa, reflexiva e ética nas diversas práticas sociais (incluindo as escolares) para se comunicar, acessar e disseminar informações, produzir conhecimentos, resolver problemas e exercer protagonismo e autoria na vida pessoal e coletiva.

6. Valorizar a diversidade de saberes e vivências culturais e apropriar-se de conhecimentos e experiências que the possibilitem entender as relações próprias do mundo do trabalho e fazer escolhas alinhadas ao exercício da cidadania e ao seu projeto de vida, com liberdade, autonomia, consciência crítica e responsabilidade.

7. Argumentar com base em fatos, dados e informações confiáveis, para formular, negociar e defender ideias, pontos de vista e decisões comuns que respeitem e promovam os direitos humanos, a consciência socioambiental e o consumo responsável em âmbito local, regional e global, com posicionamento ético em relação ao cuidado de si mesmo, dos outros e do planeta.

8. Conhecer-se, apreciar-se e cuidar de sua saúde física e emocional, compreendendo-se na diversidade humana e reconhecendo suas emoções e as dos outros, com autocrítica e capacidade para lidar com elas.

9. Exercitar a empatia, o diálogo, a resolução de conflitos e a cooperação, fazendo-se respeitar e promovendo o respeito ao outro e aos direitos humanos, com acolhimento e valorização da diversidade de indivíduos e de grupos sociais, seus saberes, identidades, culturas e potencialidades, sem preconceitos de qualquer natureza.

10. Agir pessoal e coletivamente com autonomia, responsabilidade, flexibilidade, resiliência e determinação, tomando decisões com base em princípios éticos, democráticos, inclusivos, sustentáveis e solidários (Brasil, 2018, p.9-10). 
Por competência o documento entende a mobilização que trata de “conhecimentos (conceitos e procedimentos), habilidades (práticas, cognitivas e socioemocionais), atitudes e valores para resolver demandas complexas da vida cotidiana, do pleno exercício da cidadania e do mundo do trabalho" (Brasil, 2018, p.8).

Ainda de acordo com o documento, as dez competências criadas destinamse a afirmar os "valores e estimula[r] ações que irão contribuir para a transformação da sociedade, tornando-a mais humana, socialmente justa e, também, voltada para a preservação da natureza” (Brasil, 2018, p.8). A BNCC também se mostra comprometida com a Agenda 2030 da Organização das Nações Unidas.

A saber, a Agenda 2030, criada em 2015, propõe dezessete objetivos para transformar o mundo, entre eles: erradicação da pobreza; fome zero e agricultura sustentável; saúde e bem-estar; educação de qualidade; igualdade de gênero, água potável e saneamento; energia limpa e acessível; trabalho decente e crescimento econômico; indústria, inovação e infraestrutura; redução das desigualdades ${ }^{3}$.

Muitas organizações não governamentais, se reunirão em Paris, no ano de 2015, em um evento chamado "Coalizão 21", para discutir e organizar um protesto aos objetivos da Agenda 2030. Dessa maneira, é preciso atentar-se para o fato de que uma leitura rasa da Agenda 2030 nos leva a crer que ela é totalmente inclusiva e pensada para o bem comum. O mesmo pode ocorrer com a leitura da BNCC, se a fizermos de modo superficial e não analisarmos os contextos nos quais o documento foi construído.

Para a antropóloga lara Pietricovsky, em entrevista à jornalista Amelia Gonzalez (2015), “o problema é que esses [objetivos da Agenda 2030] não mexem nas relações de produção e consumo e em outras agendas importantes para o mundo, como, por exemplo, a questão dos refugiados”. E complementa,

[...] é uma agenda que tenta dar uma face humana, tenta trabalhar em cima de mercado de carbono, de energia limpa. É palatável ao mundo

${ }^{3}$ Confira todos os objetivos em: http://www.agenda2030.com.br. Acesso em: 26 mar. 2020. 
corporativo e, assim, se mantém o sistema, o modelo. Essa é nossa leitura: a desigualdade vai continuar. Por isso existe um sentimento de muita frustração (Gonzalez, 2015).

lara Pietricovsky enfatiza que, após as políticas do Secretário-Geral da ONU, Kofi Annan, de 1997 a 2006, houve uma aproximação grande do setor privado à ONU, com proposição de reformas em todas as políticas sociais, de acordo com o interesse desse setor. "Esse processo, que temos chamado de privatização das Nações Unidas, tem acelerado" (Gonzalez, 2015), conta Pietricovsky. Como se vê, há diferentes interesses do setor privado ao se instaurar na ONU e ao definir uma agenda que não afete diretamente a produção econômica desse setor. No caso da BNCC, temos algumas instituições privadas, fundações e institutos que articularam diretamente a reforma curricular, junto ao Governo Federal, sendo a principal delas, a Fundação Lemann. A saber, temos ainda: Cenpec, Instituto Natura, Instituto Ayrton Senna, Instituto Unibanco, Fundação SM, Insper e Instituto Fernando Henrique Cardos (Peroni, Caeteno, 2015).

Portanto, o mesmo exercício crítico deve ser realizado ao lermos as dez competências gerais apresentadas pela BNCC do Ensino Médio. O ensino de competência tem sua origem em qual contexto? De que modelo de ensino estamos falando quando abordamos competências gerais? Os currículos serão pensados ainda em termos de disciplina? A disciplina de Arte seguirá existindo tal como foi prevista na Lei de Diretrizes e Bases (LDB)?

\section{O ensino por competências: diferentes aspectos}

Desde os anos 1960 e 1970, nos Estados Unidos e na Grã-Bretanha, principalmente, as competências educacionais caminham de acordo com aquilo que se espera da formação geral e profissional do futuro trabalhador. Nesse sentido, as competências mudam na medida em que as relações de produção se modificam (Ricardo, 2010). Se antes precisávamos do trabalhador para um determinado serviço manual, hoje a tecnologia, por meio de diferentes máquinas, é capaz de substituir esse tipo de mão de obra. 
Por esse motivo, a BNCC, em termos de competências e formação geral, utiliza-se da expressão "mundo do trabalho" ao invés de "mercado de trabalho", pois preparar apenas para o mercado de trabalho é limitar o jovem, em termos de oportunidades. A competência geral número seis para a Educação Básica aponta a importância de:

Valorizar a diversidade de saberes e vivências culturais e apropriar-se de conhecimentos e experiências que the possibilitem entender as relações próprias do mundo do trabalho e fazer escolhas alinhadas ao exercício da cidadania e ao seu projeto de vida, com liberdade, autonomia, consciência crítica e responsabilidade" (Brasil, 2018, p.9, grifo do autor).

Se um estudante se formar em "Técnico em Química”, por exemplo, durante o Ensino Médio Integrado, em uma Instituição Federal de Ensino, e o mercado de trabalho se tornar saturado para o exercício dessa função, essa escola teria oferecido conhecimentos, habilidades, atitudes e valores que o permitissem atuar em outra área? Ou, ainda, a instituição possibilitaria também que o estudante entrasse no sistema universitário, se assim fosse o seu desejo e se o seu contexto social the desse condições?

\section{O emprego dos sonhos e a formação técnica}

A OCDE (Organização para a Cooperação e Desenvolvimento Econômico) chama atenção em seu recente relatório, Emprego dos Sonhos?, divulgado em janeiro de 2020, que os "trabalhos dos sonhos de jovens de hoje correm risco de não existir no futuro" (Idoeta, 2020). Por meio de entrevistas realizadas com os(as) estudantes do Pisa (Programa Internacional de Avaliação de Alunos) de 2018 com cerca de 600 mil jovens de 15 anos, em 79 países, incluindo o Brasil, a OCDE descobriu que a maioria dos jovens tem as mesmas aspirações de carreira dos entrevistados durante o Pisa de 2008, ou seja, em dez anos, as aspirações quase não mudaram. Para Andreas Schleicher, diretor de educação da OCDE, "é preocupante que [os jovens] pareçam estar escolhendo seu trabalho dos sonhos a partir de uma pequena lista de ocupações populares e tradicionais" (Idoeta, 2020). 
Ainda de acordo com a OCDE, a escola precisa ir além das técnicas tradicionais de ensino, de modo que ela precisará "oferecer aos alunos o conhecimento relevante para seu futuro emprego, como também precisará desenvolver neles habilidades para que sejam pessoalmente eficientes em aplicar esse conhecimento em ambientes de mutação" (Idoeta, 2020). E mais, "boas escolas vão ajudar os jovens a se tornar pensadores críticos sobre o mercado de trabalho e sobre como ele se relaciona ao seu aprendizado" (Idoeta, 2020).

Assim, as competências gerais da BNCC têm o objetivo de possibilitar que os(as) estudantes tenham uma formação básica geral e que desenvolvam habilidades específicas para resolver as demandas complexas da vida cotidiana.

É importante enfatizar que os Institutos Federais têm conseguido, em sua maioria, realizar, de maneira exemplar, a ponte entre o ensino técnico, o conhecimento operacional validado4; ao oferecer também uma formação básica de qualidade. Os Institutos Federais, também em sua maioria, não estão subordinados às exigências do mercado de trabalho, pois a escolha dos cursos ofertados pela instituição é feita pela necessidade regional, em consulta à comunidade local. Não se trata de um ensino via treinamento tecnicista e de uma formação voltada apenas para o desenvolvimento de uma profissão. Trata-se de uma formação técnica, mas também de uma formação cidadã.

No caso do IFMG (Instituto Federal de Minas Gerais), em que sou docente de Arte, a instituição tem como missão: "ofertar ensino, pesquisa e extensão de qualidade em diferentes níveis e modalidades, focando na formação cidadã e no desenvolvimento regional". Sua visão é "ser reconhecida como instituição educacional inovadora e sustentável, socialmente inclusiva e articulada com as demandas da sociedade" e tem como valores: "ética, transparência, inovação, empreendedorismo, diversidade, inclusão, qualidade do ensino, respeito,

\footnotetext{
${ }^{4}$ Diferentemente do resultado geral do Brasil no Pisa (2016), os institutos federais e os colégios militares colocam os(as) estudantes entre os melhores do mundo. Confiram os dados completos na matéria intitulada: "Institutos federais alcançam média similar à de países desenvolvidos em exame internacional", publicada em 21 de dezembro de 2016. Disponível em: https://www2.ifmg.edu.br/portal/noticias/alunos-deinstitutos-federais-alcancam-media-de-paises-desenvolvidos-em-exame-internacional. Acesso em: 7 mar. 2021.
} 
sustentabilidade, formação profissional e humanitária, entre outros ${ }^{5 "}$.

A falta de conhecimento da potencialidade dos Institutos Federais (IFs) faz com que muitos acreditem que aos IFs são atribuídos apenas os saberes técnicos - na perspectiva individualista - e que eles estão sujeitos às relações privadas do mercado de trabalho. Tal fato pode ser exemplificado por um estudo divulgado pelo Instituto de Pesquisa Econômica Aplicada (Ipea) que "mostra um descompasso na educação brasileira: somente 25\% dos(das) estudantes formados em cursos de nível médio técnico do país acabam trabalhando em ocupações que requerem esse tipo de formação" (Ferreira, 2019).

A reportagem realizada pela jornalista Paula Ferreira, que apresenta os dados da pesquisa do Ipea, mostra que o tal descompasso dá-se pela desconexão do Ensino Técnico com o mercado de trabalho e pela preferência dos jovens em seguir a educação universitária. Segundo a jornalista, "muitos alunos concluem a formação técnica e partem para a universitária em seguida, trabalhando depois em funções que exigem esse nível” (Ferreira, 2019).

A meu ver, isso não pode ser visto como um problema. Em primeiro lugar, se a educação estiver voltada apenas para o mercado de trabalho, serão limitadas as habilidades dos(das) estudantes, como já dito. Isto é, se uma determinada profissão se tornar saturada, o mercado não conseguirá absorver todos os jovens e sua inserção posterior no mundo do trabalho se tornará ainda mais difícil.

Em segundo lugar, não é demérito da instituição se os(as) estudantes passaram no vestibular ou ENEM e resolveram seguir uma carreira acadêmica e profissional de nível superior. Muito pelo contrário, os(as) jovens estudantes, tendo uma formação básica de qualidade, enxergam a oportunidade de crescimento profissional para além da formação técnica. Em muitos casos, os(as) estudantes formados em Técnico em Química pelo IFMG Campus Betim, por exemplo, optam por fazer a licenciatura em Química ou Engenharia Química após a conclusão do Ensino Médio Integrado.

Assim, é preciso tomar cuidado com o modo como se dará a reforma do

${ }^{5}$ Disponível em: https://www2.ifmg.edu.br/portal/sobre-o-ifmg/historico-e-missao. Acesso em: 22 jan. 2020. 
Ensino Médio e a implementação da BNCC, para que não ocorra a seguinte divisão social, isto é, estudantes de escolas particulares devem desenvolver competências e habilidades para o ingresso nas universidades; já os(as) estudantes de escola pública devem desenvolver competências e habilidades limitadas ao curso técnico de formação inicial, de acordo com a demanda do mercado de trabalho.

No caso do Instituto Federal de Minas Gerais (IFMG), percebo que não há nenhum tipo de esvaziamento dos conteúdos escolares da Educação Básica. Muito pelo contrário, tais conteúdos são vistos como importantes no processo de ensino e aprendizagem para a transformação dos sujeitos na perspectiva humanista e coletiva. Cria-se diferentes tipos de projetos, sejam de ensino, pesquisa ou extensão que buscam criar, de forma interdisciplinar, em muitos casos, o aprofundamento dos conteúdos escolares.

Vejo, portanto, que não há problema no desenvolvimento de competências para ensinar e aprender, em termos de Base Nacional Comum Curricular; a dificuldade está no uso que se fará dessas competências, haverá uma divisão social entre estudantes de escolas particulares e públicas?; Quais serão os mecanismos de avaliação por meio de competências?; E ainda, qual o real interesse da Fundação Lemann, principal órgão financiador da BNCC?

A matéria citada, realizada por Paula Ferreira, é tendenciosa, por exemplo. Nela, afirma-se que os dados alarmantes da educação brasileira devem-se ao fato de os objetivos de aprendizagem não estarem alinhados ao mercado de trabalho, o que não é verdade. O fracasso escolar precisa ser pensado na perspectiva da formação cidadã, nas diferentes formas de se construir um ensino de qualidade, em uma perspectiva social, com igualdade e oportunidade comuns a todos(todas) os(as) estudantes, sejam de escolas públicas ou particulares.

\section{A noção de competência por Perrenoud}

Como uma alternativa ao fracasso escolar, Philippe Perrenoud ${ }^{6}$ tem se

6 Sociólogo suíço [1944 - ], referência no campo da avaliação e da profissionalização docente. 
apresentado como um dos principais autores a propor um método de ensino por meio de competências.

No contexto brasileiro, Ricardo (2010) enfatiza que Perrenoud não é bem compreendido e implementado nas escolas, mesmo tendo uma vasta bibliografia traduzida para o português. Segundo o autor supracitado, Perrenoud apropria-se de termos e conceitos franceses que são de difícil compreensão para o contexto brasileiro, como: "transposição didática", "contrato didático" e "práticas sociais de referências" (Ricardo, 2010).

A noção de competência, segundo Perrenoud, não se refere a uma competência específica para uma determinada área de conhecimento, mas de competências gerais para a formação dos(das) estudantes. Sendo assim, seu estudo nos interessa, ao pensarmos em uma Base Nacional Comum Curricular a todos os(as) estudantes.

Para Perrenoud, a noção de competência reside "na capacidade de mobilizar diversos recursos cognitivos para enfrentar um tipo de situações” (2000, p. 13). Assim, o autor apresenta quatro aspectos a partir dessa definição. São eles:

1. "As competências não são elas mesmas saberes, savoir-faire ou atitudes, mas mobíliam, integram e orquestram tais recursos" (Perrenoud, 2000, p.13, grifo do autor).

As competências não são conteúdos a serem trabalhados em sala de aula. Não cabe, desse modo, à BNCC do Ensino Médio definir nenhum tipo de conteúdo a ser trabalhado em sala de aula como, por exemplo, o Teatro do Oprimido de Augusto Boal.

No entanto, a partir de uma determinada competência, como a de número seis listada no início deste artigo, pode-se utilizar o Teatro do Oprimido, tanto como conhecimento da linguagem teatral em si, como também como um recurso para se trabalhar a competência seis por meio dos jogos e das metodologias de Augusto Boal que visam à liberdade, autonomia e consciência crítica presentes na competência citada. A lembrar, a competência número seis, de dez, diz que: 
valorizar a diversidade de saberes e vivências culturais e apropriar-se de conhecimentos e experiências que the possibilitem entender as relações próprias do mundo do trabalho e fazer escolhas alinhadas ao exercício da cidadania e ao seu projeto de vida, com liberdade, autonomia, consciência crítica e responsabilidade" (Brasil, 2018, p.9).

2. "Essa mobilização só é pertinente em situação, sendo cada situação singular, mesmo que se possa tratá-la em analogia com outras, já encontradas" (Perrenoud, 2000, p.14).

A competência, qualquer que seja ela, terá mais aplicabilidade se se for verdadeiramente incorporada pela escola, ou seja, não se trata apenas de uma atitude isolada de um único (única) docente, ela precisa ser trabalhada como objetivo comum da escola, da direção, do setor pedagógico e do corpo docente, levando em consideração, é claro, o contexto em que a escola está inserida. Cada contexto exige uma situação diferente e maneiras distintas de se desenvolver uma determinada competência.

3. "O exercício da competência passa por operações mentais complexas, subentendidas por esquemas de pensamento [...], que permitem determinar (mais ou menos consciente e rapidamente) e realizar (de modo mais ou menos eficaz) uma ação relativamente adaptada à situação" (Perrenoud, 2000, p.14).

Nesse ponto há uma problemática que precisa ser aprofundada. Cada vez mais as avaliações são medidas pela capacidade dos(das) estudantes de resolverem problemas complexos, como o $\mathrm{PISA}^{7}$, que avalia apenas o ensino de matemática, leitura e ciências. Nesse sentido, um jovem dito inteligente seria aquele que resolve o maior número de problemas de maneira consciente e rápida. Tal abordagem contraria a lógica do pensamento complexo que envolve o processo de criação em Arte.

Quando se pensa em termos de Arte, esse aspecto pode não funcionar. Se estudarmos o desenvolvimento do pensamento complexo apenas pela via cognitiva, racional, e nos esquecermos dos aspectos subjetivos que estão em outra

7 Programa Internacional de Avaliação de Estudantes (PISA), coordenado pela Organização para a Cooperação e Desenvolvimento Econômico (OCDE). O Pisa avalia três domínios: leitura, matemática e ciências. Em 2018, 79 países participaram do Pisa. 
esfera, a não racional e o campo sensível, os resultados da qualidade da educação e da eficiência do ensino, especificamente em Arte, podem não aparecer nos números retratados nas avaliações do Pisa. Não temos ainda, no Brasil, nenhuma metodologia de ensino para o processo de avaliação em Arte, que seja amplamente divulgada, que conseguiria transformar a experiência subjetiva do estudante em dados numéricos.

Talvez, inclusive, nunca venhamos a ter, pois a subjetividade da arte e a experiência individual do sujeito continuam sendo o foco principal das metodologias de ensino nesse campo. Desde 2002, por exemplo, muitas pesquisas em Arte apresentaram o conceito de experiência de Jorge Larrosa ${ }^{8}$, em distintas situações nos campos educacional e artístico. Em seus estudos, Larrosa mostra que onde há regularidade não há singularidade, portanto, o estudo da experiência, com toda a sua subjetividade, suas incertezas e individualidades, seria a melhor forma de compreender as diferentes maneiras de ensinar e aprender na escola. Portanto, muitas tentativas de quantificar essas experiências em dados numéricos podem fracassar.

Outro aspecto importante, que envolve os sistemas de avaliação, é que o "neoliberalismo escolar resultou [...] numa verdadeira guerra entre classes para entrar nas 'boas escolas' de um sistema escolar e universitário cada vez mais hierarquizado e desigual" (Laval, 2019, p.13).

É por esse motivo que, para Christian Laval (2019), a escola não pode ser vista como uma empresa, ditada pelos mesmos parâmetros de eficiência do mundo do trabalho na esfera capitalista. Assim, a luta por uma escola de qualidade precisa passar, em primeira instância, pela luta contra a desigualdade social que, segundo Laval, destrói as mesmas bases da escola pública. Não há como construirmos nenhum sistema educacional eficiente que favoreça as desigualdades entre diferentes classes sociais, ou que as acentue.

Ainda de acordo com Laval, não podemos esquecer que o sistema

${ }^{8}$ O conceito de experiência de Jorge Larrosa surge a partir do texto intitulado "Notas sobre a experiência e o saber de experiência” (2002). De acordo com o Google Acadêmico, esse texto já foi citado 5501 vezes por diferentes pesquisas. 
hierarquizado e, consequentemente, desigual, não é um fenômeno nacional, muito pelo contrário, trata-se de um fenômeno mundial à luz das políticas em torno do neoliberalismo.

A atual fase de globalização que afeta as escolas tem, no entanto, aspectos muito específicos que merecem ser enfatizados. Caracteriza-se pela dominação de um novo modelo de educação inspirado por uma lógica econômica do tipo liberal e pela construção de uma nova ordem educacional mundial. Governos ocidentais, elites econômicas, grandes empresas de comunicação, líderes de grandes organizações econômicas internacionais propõem em todos os principais fóruns mundiais um determinado modelo escolar, de acordo com as regras do livre comércio, as estratégias das grandes empresas multinacionais e a ideologia subjacentes a eles. Ao negar que que seus "conselhos", seus "relatórios" e suas "análises comparativas" tenham a menor dimensão normativa e prescritiva, afirmando que agem respeitando a democracia, as instituições financeiras e econômicas - mais poderosas - e que pretenderiam hoje aparecer como os porta-vozes de uma racionalidade universal. Em realidade, o modelo educacional, tal como é projetado, responde à lógica da globalização: a educação é vista de maneira redutora como um fator de produção condicionado à produtividade, à capacidade de atrair capital, à competitividade e ao emprego. Reduzir os custos quando são fornecidos pelo gasto público, introduzir mecanismos e valores de mercado e favorecer os objetivos econômicos formativos são os eixos complementares da reforma da educação defendida pelos

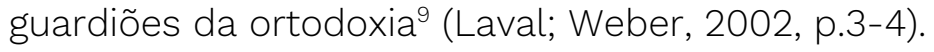

Outro ponto importante que envolve o ensino nas escolas, por meio do desenvolvimento cognitivo e dos resultados do PISA, é bem pontuado por Philippe Champy (2019). Para Champy (2019), quando os cientistas da neurociência resolvem colocar as mãos na educação, na elaboração de manuais e procedimentos pedagógicos para a educação que buscam a eficiência no trabalho

\footnotetext{
${ }^{9}$ " L'actuelle phase de mondialisation qui touche l'école a cependant des aspects très particuliers qui méritent d'être soulignés. Elle se caractérise par la domination d'un nouveau modèle d'éducation inspiré par une logique économique de type libéral et par la construction d'un nouvel ordre éducatif mondial. Les gouvernements occidentaux, les élites économiques, les grandes entreprises de communication, les dirigeants des grandes organisations économiques internationales proposent dans tous les grands forums mondiaux un certain modèle scolaire conforme aux règles du libre commerce, aux stratégies des grandes entreprises multinationales et à l'idéologie qui les sous-tendent. Niant que leurs « conseils », leurs « rapports » et leurs " analyses comparatives » aient la moindre portée normative et prescriptive, affirmant qu'elles agissent dans le respect de la démocratie, les institutions financières et économiques les plus puissantes voudraient aujourd'hui apparaitre comme les porte-parole d'une rationalité universelle. En réalité, le modèle éducatif tel qu'il est conçu répond aux logiques de la globalisation : l'éducation est regardée de façon réductrice comme un facteur de production conditionnant la productivité, la capacité d'attirer les capitaux, la compétitivité et l'emploi. En réduire les coûts quand ils sont assurés par la dépense publique, introduire les mécanismes et les valeurs du marché et privilégier les objectifs économiques de la formation sont les axes complémentaires de la réforme de l'éducation prônée par les gardiens de l'orthodoxie ». (Tradução nossa)
} 
docente e na melhora dos resultados nas avaliações dos(das) estudantes, diferentes problemáticas podem surgir nesses casos. O estudo do cérebro pode ser útil, mas está longe de revolucionar a Pedagogia, segundo Champy (2019). Ademais, ele pontua que muito do que a neurociência teorizou, em termos de conceitos, já havia sido validado por um longo tempo pelas Ciências da Educação, inclusive com resultados positivos em suas aplicações (Champy, 2019, p.216).

4. “As competências profissionais constroem-se, em formação, mais também ao saber da navegação diária de um professor, de uma situação de trabalho à outra" (Perrenoud, 2000, p.14, grifo do autor).

A navegação diária do professor ou da professora não se restringe apenas aos laços que se criam com as teorias que o docente ou a docente tenha se aprofundando e estudado durante sua formação, seja na graduação ou na pósgraduação, para o aprimoramento de suas atividades. Trata-se também de negociar e propor projetos junto com os demais colegas e a equipe da escola; de participar de reuniões que visam a desenvolver o senso de responsabilidade e de solidariedade e o sentimento de justiça com a comunidade escolar, dentre outras possibilidades, de acordo com Perrenoud (2000). Navegar e desenvolver competências profissionais é transitar em diferentes esferas da organização escolar e estar disposto a contribuir com a educação para além da sua disciplina.

\section{Sobre o contexto de criação da BNCC}

Não há consenso sobre a implementação da BNCC (Mortatti, 2015; Cury; Reis e Zanardi, 2018) no contexto brasileiro e sobre a qualidade do material homologado pelo Conselho Nacional de Educação (CNE).

Apresento diferentes variáveis, que a meu ver, podem ser analisadas nessa conjuntura, entre elas:

1) o contexto político no qual ela foi homologada, após o processo de impeachment da Presidente Dilma Rousseff;

2) os interesses das organizações privadas, como a Fundação Lemann, na 
educação pública (Peroni e Caeteno, 2015).

3) as políticas neoliberais e sua concepção de Estado mínimo;

4) a Reforma do Ensino Médio, realizada sem ampla discussão com a sociedade civil, com as organizações científicas e com as entidades dos profissionais da educação básica durante o Governo de Michel Temer;

5) a alteração da estruturação do currículo do Ensino Médio, composto pela BNCC e por itinerários formativos, que retirou o conceito de disciplinas do currículo do Ensino Médio, isto é, as competências específicas (aquilo que é específico de cada área) propostas passam a não ser mais divididas por disciplinas (Arte, Língua Portuguesa, Língua Estrangeira e Educação Física), mas por eixo formativo, sendo a Arte inserida no eixo de Linguagens e suas Tecnologias, junto com as demais disciplinas citadas.

Se recordarmos do nosso passado recente, é sabido que não houve consenso e que houve muita resistência durante a proposta de reformulação curricular ocorrida no ano de 1996 com os Parâmetros Curriculares Nacionais (PCN). Na época, muitos entendiam (Oliveira, 2004) que o documento era apenas uma iniciativa do governo espanhol, incentivada, ou exigida, pelo Banco Internacional para Reconstrução e Desenvolvimento (BIRD).

Margarida Oliveira (2004) sintetiza o pensamento de muitos pesquisadores à época. Para ela, "da forma como foram feitos [Os PCNs], na realidade, são guias que ditam não só o conteúdo programático, mas também concepção de educação, metodologia de ensino, objetivos e até forma de avaliação" (Oliveira, 2004, p.164). Desse modo, os parâmetros estariam interferindo na autonomia dos professores e das professoras de criar seus próprios currículos e metodologias de ensino.

Não se pretende aqui comparar os dois momentos de implementação de uma política nacional, em relação à reforma curricular, pois se entende que são contextos e problemáticas distintos. No entanto, o que se pontua é que os contextos político e acadêmico nem sempre estarão em sintonia para a efetivação das políticas educacionais.

Cabe a nós, portanto, fazer a crítica, debater com a sociedade civil e escrever 
sobre esse processo, mas sem deixar de lado a discussão, correndo o risco de perder historicamente o processo de implementação dessa nova política pública por não concordar com a forma como o documento foi criado e/ou com o próprio documento em si. Diferentes documentos, assim como os PCNs, têm seus problemas, mas também têm seus acertos. Logo, precisamos analisar como os gestores estão entendendo e executando a reforma curricular e se eles estão fazendo isso na perspectiva da construção de uma educação mais justa e igualitária.

Já apontei no artigo "Estudos do corpo na Base Nacional Comum Curricular do Ensino Médio" que, uma vez homologada a BNCC e em processo de implementação, é necessário fazermos uma leitura progressista do documento, uma vez que ele pode nos ajudar a frear o retrocesso causado pela extrema direita no poder em relação à educação pública emancipatória11.

De acordo com o Ministério da Educação, os sistemas de ensino deveriam ter começado o processo de discussão da BNCC em 2019, com início da implementação em 2020 e com as primeiras turmas formadas a partir da BNCC em $2022^{12}$

\section{A disciplina de Arte e sua eterna luta por sobrevivência}

A disciplina de Arte seguirá existindo tal como foi prevista na Lei de Diretrizes e Bases (LDB) se a BNCC for implementada em todos os estados e municípios do país?

De acordo com o art.26 da LDB, o ensino de Arte ainda é mantido como componente curricular obrigatório da educação básica: "Art.26 § 2o onsino da arte, especialmente em suas expressões regionais, constituirá componente

\footnotetext{
10 No prelo. A ser publicado pela Revista Contraponto, Periódico Científico do Programa de Pós-Graduação em Educação da Univali.

${ }^{11}$ Também mostro de forma mais detalhada o processo das versões da BNCC no artigo: CRUVINEL, Tiago. A avaliação qualitativa do ensino de Arte no Ensino Médio. Urdimento, Florianópolis, v. 1, n. 34, p. 77-95, 2019a.

12 Para saber mais sobre a linha do tempo com os marcos da elaboração da BNCC, acesse: http://basenacionalcomum.mec.gov.br/historico. Acesso em 7 mar. 2021.
} 
curricular obrigatório da educação básica". Ainda no mesmo artigo 26, o texto diz: "§ 6오 As artes visuais, a dança, a música e o teatro são as linguagens que constituirão o componente curricular de que trata o $\S 2$ este artigo".

Desse modo, uma leitura simples da legislação atual nos permitiria concluir que, sim, a disciplina de Arte seguirá sendo obrigatória. No entanto, precisamos compreender melhor o que a BNCC entende por unidade curricular.

De acordo com o Guia de implementação do novo Ensino Médio elaborado pelo Ministério da Educação e pelo Conselho Nacional dos Secretários Estaduais de Educação, as unidades curriculares são:

\begin{abstract}
Os elementos com carga horária pré-definida cujo objetivo é desenvolver competências específicas, seja da formação geral básica, seja dos itinerários formativos. Além da tradicional organização por disciplinas, as redes e escolas podem escolher criar unidades que melhor respondam aos seus contextos e às suas condições, como projetos, oficinas, atividades e práticas contextualizadas, entre outras situações de trabalho (Brasil, 2019, p.14).
\end{abstract}

Portanto, manter o formato em disciplinas de maneira tradicional ainda parece ser uma escolha das redes estaduais e das escolas. De modo que, se é uma escolha, pode ocorrer de determinados estados e municípios optarem por não trabalharem com o conceito de disciplina o seu formato tradicional, como ocorre hoje. Além disso, a escola que ainda não tem o professor(a) formado(a) especificamente em Arte (Artes Visuais, Música, Dança ou Teatro) preferirá contratar um(a) professor(a) mais generalista da área de Linguagem, podendo esse(essa) docente ter formação na área de Língua Portuguesa, Língua Estrangeira ou Educação Física.

É importante lembrar que a LDB fala da obrigatoriedade do ensino de Arte, mas ela não diz que o conteúdo deverá ser ministrado apenas por profissionais licenciados na área. Embora a constatação seja óbvia, a lei não deixa isso explícito. Nesse caso, a escola poderá escolher romper com o conceito tradicional de disciplina e não contratar mais nenhum (nenhuma) docente específico(a) de Arte.

Além disso, é possível que sejam propostos projetos e oficinas que, segundo 
o guia de implementação da BNCC, podem ocorrer por meio do desenvolvimento de núcleos de criação artísticas que irão trabalhar:

[...] processos criativos e colaborativos, com base nos interesses de pesquisa dos jovens e na investigação das corporalidades, espacialidades, musicalidades, textualidades literárias e teatralidades presentes em suas vidas e nas manifestações culturais das suas comunidades, articulando a prática de criação artística com a apreciação, análise e reflexão sobre referencias históricas, estéticas, sociais e culturais (artes integradas, videoarte, performance, intervenções urbanas, cinema, fotografia, slam, hip hop etc.) (Brasil, 2019, p.14).

Na minha opinião, qualquer núcleo de criação artística só será efetivo se houver profissionais qualificados e formados na área. Isso não quer dizer que um docente ou uma docente de língua portuguesa não possa propor um trabalho artístico interdisciplinar cujo resultado será a criação de um processo criativo e colaborativo em Teatro, por exemplo. No entanto, é preciso aqui reafirmar que as formações específicas em Arte qualificam o(a) docente a trabalhar diferentes metodologias de ensino que não são ensinadas nos cursos de Letras nas universidades públicas.

A ideia de núcleo de criação artística pode ser interessante de ser implementada nas escolas e se mostra atual, ao propor diferentes referenciais e linguagens artísticas a serem trabalhadas. Contudo, é dever da escola, dos estados e dos municípios zelarem pela qualidade da educação em Arte, o que só se dará, de forma majoritária, com a contratação de profissionais da área que consigam formular os núcleos de criação artística de maneira eficiente para todos(todas) os(as) estudantes que deles fizerem parte.

Além disso, a BNCC propõe a criação, na área de Linguagens e suas Tecnologias, do que se chamou de "campo artístico", que visa a ser um

espaço de circulação das manifestações artísticas em geral, contribuindo para a construção da apreciação estética, significativa para a constituição de identidades, a vivência de processos criativos, o reconhecimento da diversidade e da multiculturalidade e a expressão de sentimentos e emoções. Possibilita aos estudantes, portanto, reconhecer, valorizar, fruir e produzir tais manifestações, com base em critérios estéticos e no 
exercício da sensibilidade (Brasil, 2018, p. 489).

Penso, que não há como criar esse tipo específico de campo artístico, conforme a citação acima, se não houver o(a) docente específico(a) da área de Arte na escola, seja de Música, Teatro, Dança ou Artes Visuais, pois ele(ela) estudou diferentes manifestações artísticas tanto do ponto de vista prático quanto teórico. Relegar essa função a outro profissional, que pode nunca ter tido experiência prática com as Artes no contexto acadêmico, e muito menos formação específica, é dizer que qualquer docente pode ensinar qualquer matéria, desde que a ele the seja atribuída tal função.

\section{Considerações finais}

Os dilemas que iremos enfrentar com a BNCC, em primeiro lugar, relacionamse à forma como serão pensadas as disciplinas em termos de unidade escolar. Se a escola, via autonomia ou via Secretaria de Educação de seu estado, optar por manter o conceito tradicional de disciplina, e a Arte, assim como as demais, for reestruturada apenas em termos de itinerário formativo, o mais importante será o(a) docente se preocupar em ter uma leitura progressista da BNCC. Além disso, entendo que é preciso trabalhar as competências em sua disciplina de modo emancipatório. Os(as) estudantes precisam ter uma formação artística e humana de qualidade.

Caso a escola, de forma autônoma, ou por meio das Secretarias de Educação, resolva acabar com o conceito de disciplina para todas as matérias e decida criar os núcleos de criação artística, será necessário lutarmos pela manutenção e contratação de docentes de Arte para comporem esses núcleos de criação, como já dito acima. Além disso, voltamos à nossa infelizmente eterna luta por espaços físicos e pela compra de materiais necessários que nos permitam ensinar a disciplina de Arte, seja no campo das Artes Visuais, da Música, do Teatro ou da Dança.

Essa luta, que vem de anos, não pode parar. A batalha por espaço físico e político será uma constante para todos os formados em Arte. Nunca estaremos a 
salvo. Talvez possamos experimentar certo alívio se os governantes do momento tiverem uma visão mais humana sobre a formação de nossos(nossas) estudantes. Contudo, nunca podemos garantir que eles estarão sempre lá para lutar pela implementação daquilo que já está em lei, visto que a Arte é componente curricular obrigatório na Educação Básica. Isto é, independentemente da forma como a escola irá fazer o processo de implementação da BNCC, a lei maior é a LBD, que deixou clara a questão da obrigatoriedade. Podendo, se for o caso, acionar o Ministério Público para verificar o descumprimento da lei ou judicializar a questão, de modo pessoal ou coletivo, por meio de uma ação, quando houver a ausência da Arte na unidade curricular da escola.

\section{Referências}

BRASIL. Base Nacional Comum Curricular: Ensino Médio. Brasília: MEC/Secretaria de Educação Básica, 2018.

BRASIL. Guia de implementação do novo Ensino Médio. Brasília: MEC/Conselho Nacional dos Secretários estaduais de Educação, 2019.

CHAMPY, Philippe. Vers une nouvelle guerre scolaire. Quand les technocrates et les neuroscientifiques mettent la main sur l'Éducation nationale. Paris: Éditions La Découverte, 2019.

CRUVINEL, Tiago. A avaliação qualitativa do ensino de Arte no Ensino Médio. Urdimento, Florianópolis, v. 1, n. 34, p. 77-95, 2019 a.

CRUVINEL, Tiago. Estudos do corpo na Base Nacional Comum Curricular do Ensino Médio. In: Revista Científica do Programa de Pós-Graduação em Educação da Universidade do Vale do Itajaí - UNIVALI. (No prelo).

CURY, CARLOS ROBERTO; REIS, M.; ZANARDI, T. Base Nacional Comum Curricular: dilemas e perspectivas. 1a. ed. São Paulo: Cortez, 2018. v. 1. 141p .

FERREIRA, Paula. Maioria dos alunos do ensino técnico não trabalha em sua área. O Globo. 2019. Disponível em:

https://oglobo.globo.com/sociedade/educacao/maioria-dos-alunos-do-ensinotecnico-nao-trabalha-em-sua-area-23479583. Acesso em: 23 jan. 2020.

GONZALEZ, Amelia. Organizações preparam protesto contra Objetivos da ONU para Desenvolvimento Sustentável. G1.globo.com. Rio de Janeiro, 03 de out. 2015. 
Disponível em: http://g1.globo.com/natureza/blog/nova-eticasocial/post/organizacoes-preparam-protesto-contra-objetivos-da-onu-paradesenvolvimento-sustentavel.html. Acesso em: 15 jan. 2020.

IDOETA, Paula. Trabalhos dos sonhos de hoje correm risco de não existir no futuro, diz OCDE. BBC News Brasil em São Paulo. 2020. Disponível em: https://www.bbc.com/portuguese/internacional-51198292. Acesso em: 23 abr. 2020.

LAVAL, Christian; WEBER, Louis (orgs.). Le Nouvel Ordre éducatif mondial. Paris, Syllepse, 2002. Disponível em:

http://institut.fsu.fr/IMG/pdf/Le nouvel ordre educatif mondial.pdf. Acesso em: 30 jan. 2020.

LAVAL, Christian. A escola não é uma empresa: o neoliberalismo em ataque ao ensino público. Tradução Mariana Echalar. São Paulo: Boitempo, 2019.

LARROSA, Jorge. Notas sobre a experiência e o saber de experiência. Revista Brasileira de Educação, n. 19, Jan./Fev./Mar./Abr. 2002.

MORTATTI, Maria do Rosário. 'Essa' Base Nacional Comum Curricular: mais uma tragédia brasileira?. Revista brasileira de alfabetização, v. 2, p. 191-2015, 2015.

OLIVEIRA, Margarida. O PCN de História e a ANPUH: embate acadêmico e político. Saeculum (UFPB), João Pessoa - PB, n.10, p. 163-183, 2004.

PERONI, Vera Maria Vidal; CAETENO, Maria Raquel. O público e o privado na educação-Projetos em disputa?. Retratos da Escola, v. 9, n. 17, 2015.

PERRENOUD, Philippe. Dez novas competências para ensinar. Porto Alegre: Artmed, 2000 .

RICARDO, Elio. Discussão acerca do ensino por competências: problemas e alternativas. Cadernos de Pesquisa, v.40, n.140, p. 605-628, maio/ago. 2010.

Recebido em: 28/10/2020

Aprovado em: 09/03/2021 